\title{
Exercise testing after beta-blockade: improved specificity and predictive value in detecting coronary heart disease
}

\author{
J MARCOMICHELAKIS, R DONALDSON, J GREEN, S JOSEPH, H B KELLY,* \\ P TAGGART, W SOMERVILLE
}

From the Department of Cardiology, The Middlesex Hospital, London

SUMMARY The value of exercise testing in detecting myocardial ischaemia resulting from coronary atheroma remains controversial. In order to increase the reliability of exercise testing, all its components (symptomatic, haemodynamic, and electrocardiographic) have been scrutinised. In this study, concerned only with the electrocardiographic response to exercise, the incorporation of beta-blockade into the standard exercise procedure has improved specificity and predictive value without affecting sensitivity.

Fifty patients with anginal pain and 50 asymptomatic subjects with an abnormal electrocardiogram were investigated by exercise testing before and after beta-blockade (oxprenolol). All subjects had coronary arteriograms and left ventriculograms, and the results of exercise testing were related to the presence or absence of obstructive coronary artery disease. Possible causes of false positive exercise tests were eliminated by echocardiography. Though beta-blockade was unreliable in distinguishing ischaemic from non-ischaemic resting electrocardiograms, it eliminated all the false positive electrocardiographic responses to exercise in both groups and did not abolish any of the true positive electrocardiographic responses. Thus, specificity and predictive value were improved without reduction in sensitivity.

This technique may not necessarily be applicable to other groups of patients or to a random population, but the results of this study suggest it will be a useful additional routine procedure in the investigation of coronary heart disease.

The routine use of exercise testing to detect coronary heart disease remains controversial. ${ }^{1-3}$ When applied to symptomatic patients with chest pain, where the prevalence of coronary heart disease is high, the reliability of this test is also high, but it may be argued that the diagnosis can usually be established by history alone. When applied to asymptomatic subjects, however, where the prevalence of the disease is low, the number of false positive results is high and consequently the specificity and predictive value (Table 1) of the exercise test are poor. ${ }^{4-6}$ Positive exercise tests in asymptomatic apparently healthy persons, who have an electrocardiogram indistinguishable from that of myocardial ischaemia, present difficult problems familiar to those who use electrocardiography for routine screening and the exercise test

^ Present address: The Royal Air Force Central Medical Establishment.

Received for publication 6 July 1979 as a further aid to diagnosis. The exercise test may then compound the problem rather than solve it.

\section{Table 1 Glossary of terms}

Sensitivity $=$ percentage of all patients with disease who manifest an abnormal test

$$
=\frac{\mathrm{TP}}{\mathrm{TP}+\mathrm{FN}} \times 100 \%
$$

Specificity $=$ percentage of negative results in subjects without the disease

$$
=\frac{\mathrm{TN}}{\mathrm{TN}+\mathrm{FP}} \times 100 \%
$$

Predictive value $=$ percentage of positive results that are true positive

$$
=\frac{\mathbf{T P}}{\mathbf{T P}+\mathbf{F P}} \times 100 \%
$$

TP, true positive; FP, false positive; TN, true negative; FN, false negative. 
The distinction between false and true positive exercise tests can be made only by coronary arteriography, but this is not usually performed in asymptomatic patients, not only because it is an expensive procedure with an element of risk, but also because precise diagnosis does not lead to specific treatment or improved prognosis. Where, however, an acute coronary event could place both patient and others at risk, precise diagnosis becomes essential. Public service vehicle drivers, pilots, and air traffic controllers are typical examples. The removal from duty of all asymptomatic pilots and air traffic control officers with positive exercise tests would eliminate many who are free from disease, highly trained, and experienced. Though the group with positive exercise tests appears at high risk of a coronary incident, there will be a greater absolute number of subjects who develop such incidents among the group with negative exercise tests because this population is much larger. ${ }^{7}$ There has, therefore, been objection to the use of exercise testing as a screening device in asymptomatic personnel. It is difficult, however, to avoid the use of exercise testing in subjects with abnormal resting electrocardiograms; when such testing is positive, coronary arteriography becomes necessary to distinguish those with coronary heart disease from those without, if the subjects wish to continue in their profession. This indicates a clear need for an alternative, simple, and safe method for making this distinction.

A recent report ${ }^{8}$ suggests that many fit, asymptomatic subjects, with normal coronary arteries and resting electrocardiographic changes indistinguishable from those of myocardial ischaemia, have a positive electrocardiographic response to exercise. The exercise-induced changes have been mimicked by low-dose adrenaline infusion combined with atrial pacing. Plasma catecholamine estimations in such persons indicate that the electrocardiographic features reflect altered response to normal adrenaline concentrations, rather than adrenaline hypersecretion. As beta-blockade is capable of blocking this adrenergic response, it seemed appropriate to investigate the effect of beta-adrenergic blockade on the electrocardiographic response to exercise.

\section{Subjects and methods}

One hundred men were investigated; 50 were patients presenting with angina and 50 were asymptomatic subjects with abnormal resting electrocardiograms suggesting myocardial ischaemia. Though subjects were selected for each group on the basis of angina or an abnormal electrocardiogram, there was no selection within the groups.
Group 1 contained 50 consecutive patients selected for coronary arteriography because of angina. All were men aged between 32 and 64 years (mean 48). Patients with evidence of previous myocardial infarction or whose electrocardiogram showed bundle-branch block or other conduction abnormality were not admitted to the study. None had evidence of valvar heart disease or systemic hypertension.

Group 2 contained 50 consecutive asymptomatic subjects referred for investigation of an abnormal resting electrocardiogram which showed ST-T changes indistinguishable from those of myocardial ischaemia. All were men aged 17 to 57 years (mean 37). Most were civilian or military aircrew or air traffic control officers who had undergone routine electrocardiography. Subjects with echocardiographic features suggesting cardiomyopathy, asymmetric septal hypertrophy, or prolapsing mitral valve were not included in the study. In no case was there any evidence of valvar heart disease, systemic hypertension, or conduction abnormality.

All subjects were admitted to hospital and were investigated as follows.

\section{RESTING ELECTROCARDIOGRAPHY}

Resting 12 lead electrocardiograms were recorded on a three-channel Mingograf Recorder, without prior medication and, on a separate occasion, one and a half to two hours after a single oral dose of $80 \mathrm{mg}$ of the beta-adrenergic blocking agent oxprenolol (Trasicor). No subject received any medication except glyceryl trinitrate for three days preceding the study; digitalis, beta-adrenergic blocking agents, diuretics, and other drugs were omitted. Electrocardiograms were recorded in the lying and standing positions, during 30 seconds of hyperventilation, and during the Valsalva manoeuvre.

\section{ECHOCARDIOGRAPHY}

M-mode echocardiography was performed without beta-adrenergic blockade, using a Smith Kline Ekoline $20 \mathrm{~A}$ and a $2.25 \mathrm{MHz}$ transducer focused at $7.5 \mathrm{~cm}$, coupled to a Cambridge six-channel fibreoptic recorder. Recordings were made with the patient lying on his left side with the head of the bed raised to about 30 degrees.

The interventricular septal and left ventricular posterior wall echoes were recorded at both mitral and submitral level. The ratio of interventricular septal to left ventricular posterior wall thickness was considered abnormal if greater than $1 \cdot 3$, corrected for age. 
TREADMILL EXERCISE TESTING

Maximal treadmill exercise tests were performed on each patient on two occasions using a threechannel Avionics monitor model 3000 and a computer programmer P100. The first test was performed without medication ('unblocked') and the second test one and a half to two hours after oral oxprenolol $80 \mathrm{mg}$ ('blocked'). The adequacy of beta-blockade was confirmed by 15 to 20 per cent reduction in the resting and exercise heart rate. No subject received food or drink for three hours before the test. The procedure described by Bruce was adopted, ${ }^{9}$ and the CM lead system was used to record three praecordial leads at the end of each stage and every minute during a 10-minute recovery period, with the subject recumbent. The three praecordial leads were positioned after inspection of the resting electrocardiogram in order to include lead positions where maximum changes had been observed. CM5 was included in each case. Blood pressure measurements were made using a cuff sphygmomanometer at rest, before exercise, 30 seconds before the end of each stage, and every minute during the recovery period. In one subject the treadmill exercise test was repeated on a third occasion after $160 \mathrm{mg}$ oxprenolol, when $80 \mathrm{mg}$ had failed to slow resting and maximal exercise heart rates by 15 per cent. The end-point was the limit of endurance, determined by fatigue, breathlessness, or severe chest pain, rather than target heart rate.

The criteria for a positive electrocardiographic exercise test were the development of, or an increase in, pre-existing ST segment depression of $1 \mathrm{~mm}$ or more relative to the TP segment, measured $80 \mathrm{~ms}$ after the nadir of the $S$ wave in at least six consecutive beats, irrespective of whether the ST segment was upsloping, horizontal, or downsloping. A 'blocked' test was considered negative when there was less than $1 \mathrm{~mm}$ ST depression irrespective of the heart rate achieved. We also considered as negative those electrocardiographic responses which, though abnormal during the early stages of exercise and late recovery period, showed normal electrocardiographic configuration at maximum and near maximum heart rate.

\section{CATHETERISATION STUDIES}

Left heart catheterisation and coronary arteriography, by Sones or Judkins technique, were performed on all 100 patients. Left ventricular enddiastolic pressure was measured. Single plane left ventriculograms were obtained in the $30^{\circ}$ right anterior oblique position at $\mathbf{4 0}$ frames per second, and coronary arteriograms were obtained in the anteroposterior, left anterior oblique, and right anterior oblique positions. Narrowing of coronary artery lumen by more than 50 per cent was considered obstructive. Coronary arteriography was performed within a month of the exercise test. No attempt was made to provoke coronary spasm.

\section{Results}

\section{RESTING ELECTROCARDIOGRAPHY \\ Group 1}

Thirty-four of the 50 patients with angina had abnormal resting electrocardiograms indicating myocardial ischaemia (ST segment and $\mathrm{T}$ wave changes). In eight of the 34 with ischaemic abnormalities the changes were greater in the standing position. Hyperventilation and the Valsalva manoeuvre produced inconstant effects.

After beta-blockade, 15 out of 34 abnormal electrocardiograms became normal (Fig. 1), eight improved but did not become normal, and 11 were unchanged. In the eight whose ischaemic abnormalities were exaggerated in the standing position, the postural effect was less after beta-blockade.

In this group, the resting heart rates ranged from 58 to 90 beats per minute (mean 70 ).

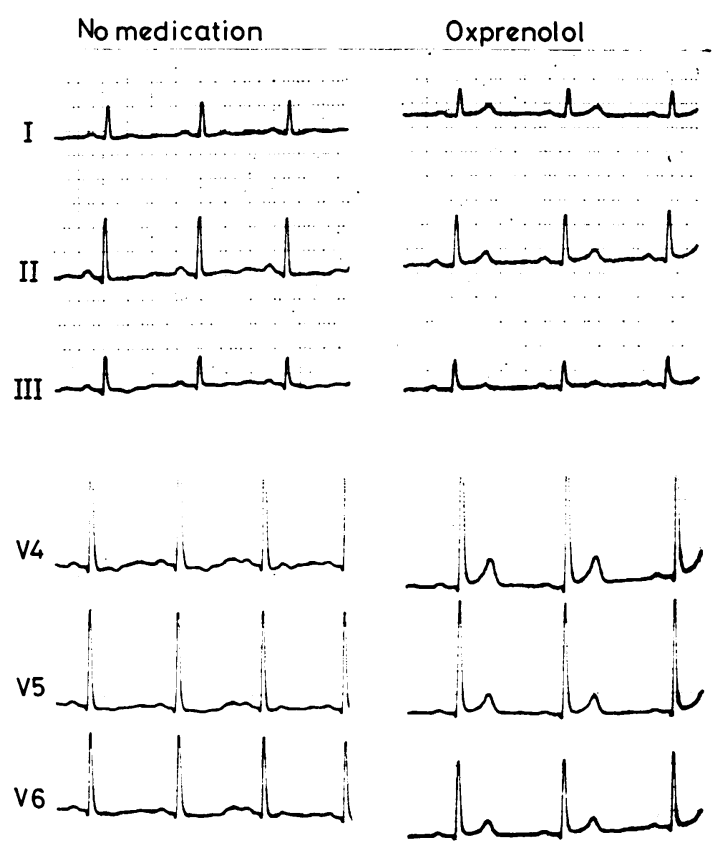

Fig. 1 Resting electrocardiograms of a patient with angina and an abnormal coronary arteriogram. Leftabnormal, without medication. Right-normal, one and a half hours after $80 \mathrm{mg}$ oxprenolol. 


\section{Group 2}

All 50 asymptomatic men had abnormal electrocardiograms on admission or during the previous six months. These changes included ST segment depression and/or low amplitude, flat, or inverted

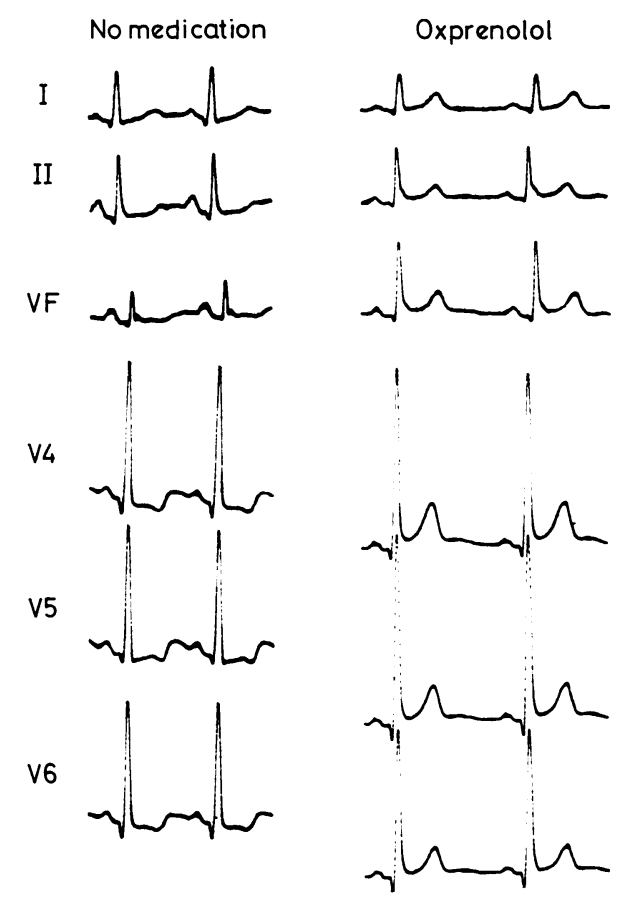

Fig. 2 Resting electrocardiograms of an asymptomatic subject with a normal coronary arteriogram. Leftabnormal, without medication. Right-normal, one and a half hours after $80 \mathrm{mg}$ oxprenolol.
T waves. In 40 of the 50 men the abnormal electrocardiogram became normal after beta-blockade (Fig. 2), in eight it improved, and in two it was unaffected. In 15 out of 50 the changes were more prominent in the standing position and this postural effect was abolished by an oral dose of oxprenolol $80 \mathrm{mg}$ (Fig. 3). Hyperventilation and the Valsalva manoeuvre produced variable and inconstant effects.

In this group, the resting heart rate ranged from 56 to 86 beats per minute (mean 75 ).

\section{ECHOCARDIOGRAPHY \\ Group 1}

No patient in this group showed disproportionate hypertrophy of the interventricular septum, narrow left ventricular outflow tract, or dynamic outflow tract obstruction with anterior mitral valve motion during systole. No patient showed echoes from prolapsing mitral leaflets. Eight patients had echocardiograms showing reduced interventricular septal or left ventricular posterior wall motion. The remaining 42 had normal echocardiograms.

\section{Group 2}

None of the 50 subjects had asymmetric septal hypertrophy, or other features to suggest cardiomyopathy or prolapsing mitral leaflets. However, in many of them the interventricular septum was found to be slightly thicker than in normal subjects of the same age though the difference was not significant.

\section{EXERCISE TESTING}

Group 1

As shown in Table 2, there was a definite positive
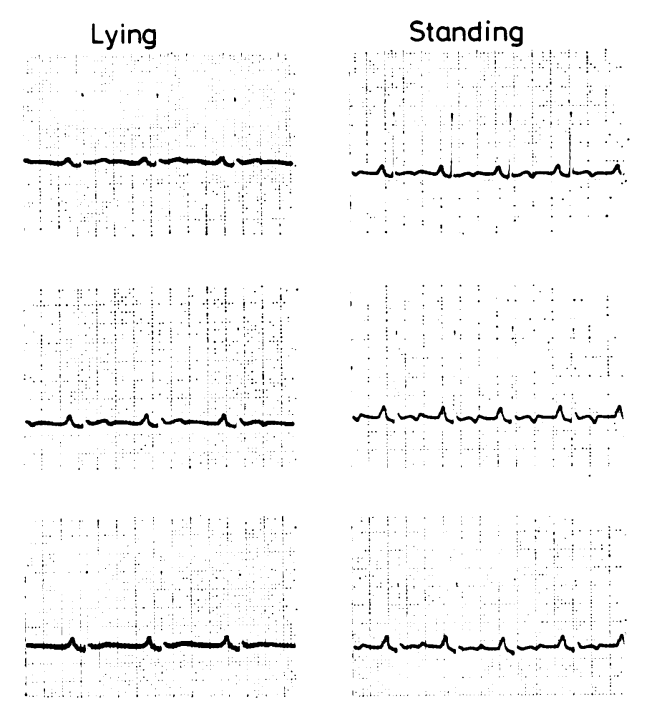

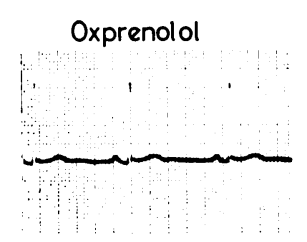

Fig. 3 Effect of beta-blockade on postural changes in the resting electrocardiogram. Left-lying, without medication. Centrestanding, without medication. Right-standing, one and a half hours after $80 \mathrm{mg}$ oxprenolol. 
electrocardiographic response in 'unblocked' tests in 44 of the 50 patients and a definite negative electrocardiographic response in the other six, no test being borderline. When the tests were repeated after oxprenolol, the responses remained positive in 43 and became normal in one. Coronary arteriography confirmed coronary heart disease in the $\mathbf{4 3}$

\section{Nomedication Oxprenolol}

Control

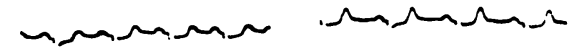

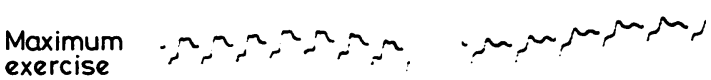

Recovery

$1 \mathrm{~min}$

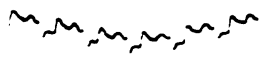

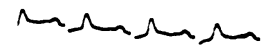

$3 \mathrm{~min}$

$$
\sqrt[r]{n} \sqrt[r]{ } \sim
$$

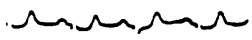

$7 \mathrm{~min}$

นกนกนก

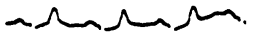

Fig. 4 Exercise electrocardiograms of a patient with angina and an abnormal coronary arteriogram. Leftpositive electrocardiographic response, without medication. Right-positive electrocardiographic response, one and a half hours after $80 \mathrm{mg}$ oxprenolol.

\section{NOMEDICATION}

\section{OXPRENOLOL}
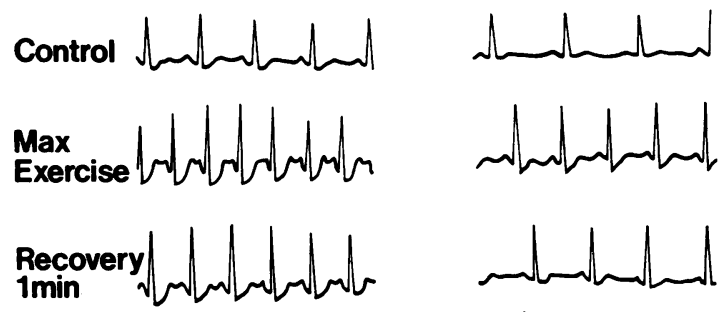

$3 \mathrm{~min}$

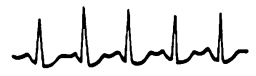

$7 \mathrm{~min}$
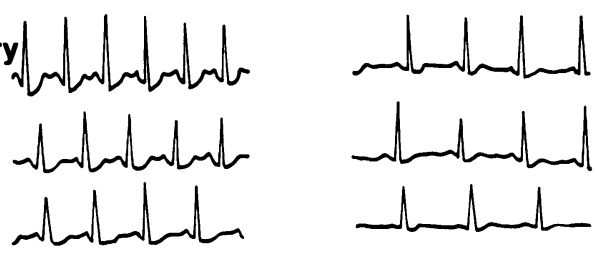

Fig. 5 Exercise electrocardiograms of a patient with angina and an abnormal coronary arteriogram. Leftpositive electrocardiographic response, without medication. Right-positive electrocardiographic response, one and a half hours after $80 \mathrm{mg}$ oxprenolol. whose electrocardiographic response had remained positive after beta-blockade; the one whose response became normal had a normal coronary arteriogram, though the clinical diagnosis of angina was difficult to refute. In the 43 patients whose positive electrocardiographic response persisted after beta-blockade, the degree of the ST segment depression was usually reduced (Fig. 4). The closest approximation to a normal exercise electrocardiogram in this group of 43 patients is illustrated in Fig. 5, though, with strict application of the defined criteria, even this test remained unequivocally positive. The six negative electrocardiographic responses to the 'unblocked' exercise test remained negative after beta-blockade.

\section{Group 2}

As shown in Table 3, a positive electrocardiographic response to exercise was recorded in 'unblocked' tests in 20 of the 50 subjects and a negative response in 30 . When the test was repeated after beta-blockade, the electrocardiographic response became normal in 19 out of the 20 (Fig. 6) and in these 19 the coronary arteriogram was subsequently shown to be normal. In the remaining one, however, the electrocardiographic response to exercise remained positive, though the degree of ST segment depression was reduced. The 30 negative 'unblocked' tests were unaffected by beta-blockade, and coronary arteriography confirmed the absence of obstruction. In eight of these 30 negative responses, the electrocardiogram was abnormal during the beginning of the 'unblocked' test, became normal during exercise, and returned to the original abnormal pattern during the recovery period. However, beta-blockade abolished these electro-

Table 2 Group 1: Exercise test results on 50 patients with angina

\begin{tabular}{lc}
\hline No medication & Oxprenolol \\
\hline $44+\mathrm{ve}(43 \mathrm{TP}+1 \mathrm{FP})$ & $\begin{array}{r}43+\mathrm{ve}(43 \mathrm{TP}+0 \mathrm{FP}) \\
6-\mathrm{ve}(3 \mathrm{TN}+3 \mathrm{FN})\end{array}$ \\
\hline
\end{tabular}

TP, true positive; FP, false positive; TN, true negative; $F N$, false negative; + ve, positive; - ve, negative.

Table 3 Group 2 : Exercise test results on 50 symptomless subjects with abnormal electrocardiogram

\begin{tabular}{lc}
\hline No medication & Oxprenolol \\
\hline $20+\operatorname{ve}(1 \mathrm{TP}+19 \mathrm{FP})$ & $1+\mathrm{ve}(1 \mathrm{TP}+0 \mathrm{FP})$ \\
$30-\mathrm{ve}(29 \mathrm{TN}+1 \mathrm{FN})$ & $49-\mathrm{ve}(48 \mathrm{TN}+1 \mathrm{FN})$
\end{tabular}

Abbreviations as in Table 2. 
cardiographic changes, and the test became normal throughout (Fig. 7). The end-point of exercise (limit of endurance) was in many cases beyond the point of the age-predicted maximal heart rate.

One subject was of particular interest. This 30year-old asymptomatic man with unobstructed coronary arteries had a positive electrocardiographic response to exercise before and after oxprenolol. However, the resting heart rate before the second test was not significantly decreased, suggesting inadequate blockade. In fact, this man had shown exceptional sensitivity to adrenaline infusion in a separate study. Because of these observations, treadmill exercise was repeated a third time, after oxprenolol $160 \mathrm{mg}$. The resting heart rate then slowed and subsequent exercise tracings were all completely normal (Fig. 8).

\section{CATHETER STUDIES}

\section{Group 1}

Coronary arteriography showed that 46 of the 50 subjects had at least 70 per cent arterial narrowing in one or more vessels. Of these 46 with coronary

\section{Rest}
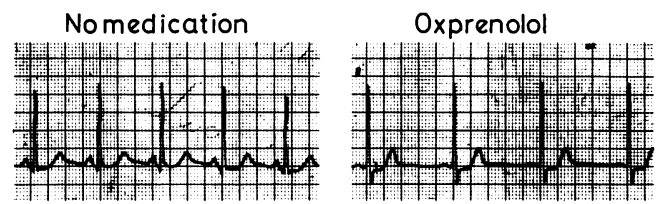

II
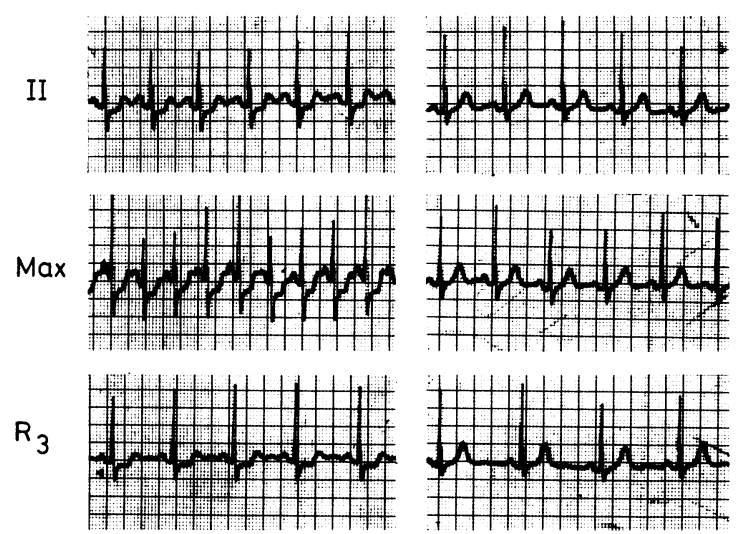

$\mathrm{R}_{5}$
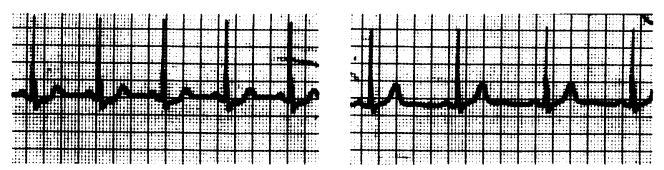

Fig. 6 Exercise electrocardiograms of an asymptomatic subject with a normal coronary arteriogram. Leftpositive, without medication. Right-negative, one and a half hours after $80 \mathrm{mg}$ oxprenolol. heart disease, 43 had a positive electrocardiographic response to exercise after blockade, and three had false negative responses. Of the 43 , eight had threevessel disease, 17 had two-vessel disease, and 18 had one-vessel disease. Of the three with false negative electrocardiographic responses to exercise, one had two-vessel disease and two had one-vessel disease. The one patient whose positive electrocardiographic response to the 'unblocked' test was normal after beta-blockade, together with the remaining three with negative electrocardiographic responses to 'blocked' tests, had normal coronary arteries.

\section{Group 2}

Coronary arteriography showed that two out of the 50 subjects with abnormal electrocardiograms had
Nomedication

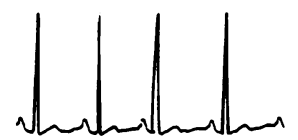

لـ

$\ln |\sin |$

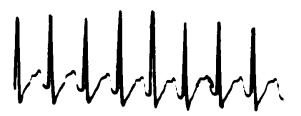

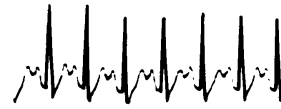

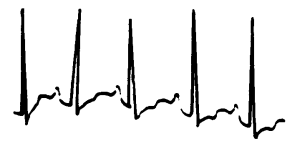<smiles>CCCCNCC(C)C</smiles>

$80 \mathrm{mg}$ Oxprenolol

Rest<smiles>CCCCCCCCCC</smiles>

SI

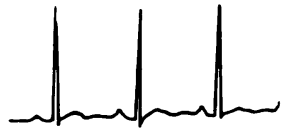

SIII<smiles>CCCCCNC(C)CC</smiles>

$\operatorname{Max}$

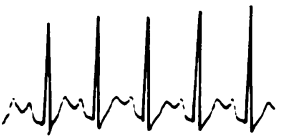

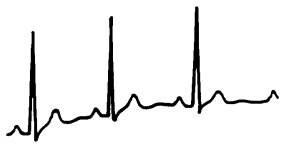

R3

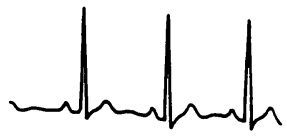

R 5

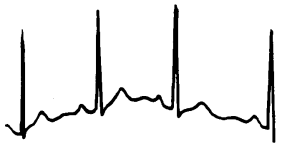

Fig. 7 Exercise electrocardiograms of an asymptomatic subject with a normal coronary arteriogram. Leftelectrocardiographic changes during early and recovery phases, negative at maximum, without medication. Rightnegative, one and a half hours after $80 \mathrm{mg}$ oxprenolol. $S$, stage of exercise procedure; $R$, recovery period. 
obstructed coronary arteries. One of these two had positive electrocardiographic responses to exercise both before and after beta-blockade, and coronary arteriography showed 80 per cent proximal narrowing of the right coronary artery, 80 per cent stenosis of the circumflex, and a minor lesion in the anterior descending coronary artery. The other one had a negative electrocardiographic response to exercise both before and after beta-blockade; this was a false negative response, as coronary arteriography revealed 70 per cent narrowing of his right coronary artery. Of the remaining 48,47 had normal coronary arteries, and one had an obstruction of less than 50 per cent of his left anterior descending coronary artery.

\section{Discussion}

The risk, high cost, and discomfort of coronary arteriography make it an unsuitable procedure for general use. Therefore, the development of reliable non-invasive methods for the detection of myocardial ischaemia remains one of the more important challenges for diagnostic cardiology. High sensitivity and specificity for the detection of myocardial ischaemia have been claimed for thallium-201 myocardial imaging, ${ }^{10} 11$ though not in all reports, ${ }^{12}$ and application is limited by cost of both imaging agent and imaging apparatus. The technique will probably be more widely used, but the improvement of existing inexpensive methods would be of more immediate value.

Responses to exercise other than electrocardio- graphic changes have been assessed. ${ }^{13} 14$ These include the symptomatic response to exercise, the development of anginal pain, ${ }^{14}$ and the haemodynamic response, blood pressure and heart rate changes. ${ }^{15} 16$ Attempts to increase the reliability of the test have recently been made, ${ }^{17-19}$ using such multivariate criteria. There is no doubt that these methods will further increase the accuracy of exercise testing. However, this study is concerned only with the electrocardiographic response to exercise.

The specificity of the electrocardiographic response to maximal exercise testing for detection of myocardial ischaemia, using both epidemiological and coronary arteriographic methods of control, is 90 to 93 per cent. ${ }^{20-22}$ Any test which falsely identifies up to 10 per cent of subjects as having coronary artery disease has serious limitations as a screening method, especially when those subjects depend on a normal result for their livelihood. Various methods have therefore been used in an attempt to improve the diagnostic accuracy of electrocardiographic response to exercise. For example, increasing the workload improves sensitivity, but results in a higher number of false positive tests because of the inverse relation between sensitivity and specificity in all forms of exercise testing; similarly, changing the criterion for positivity from 1 to $2 \mathrm{~mm}$ ST segment depression results in an increase in specificity but a decrease in sensitivity.

Electrocardiographic ST and $\mathrm{T}$ wave changes occurring at rest may be caused by several organic and non-organic conditions. They may result from coronary heart disease and other organic conditions,

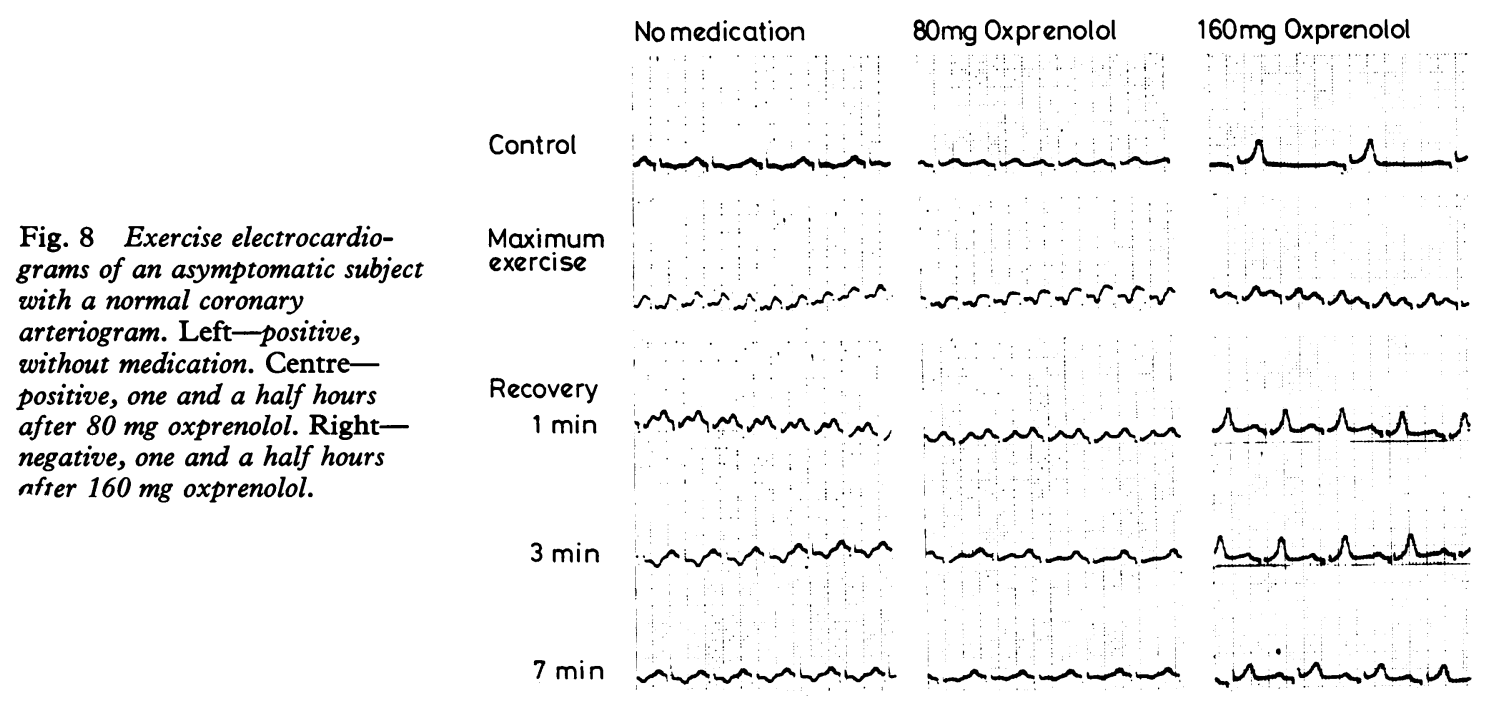


or they may be functional as in neurocirculatory asthenia ${ }^{23}$, the hyperkinetic heart syndrome, ${ }^{24}$ postural changes, ${ }^{25}$ hyperventilation, ${ }^{26}$ and emotion. ${ }^{27}$ Beta-blockers can lessen and sometimes abolish these resting electrocardiographic changes irrespective of their cause, as has been shown when these result from coronary atherosclerosis, ${ }^{28}$ the hyperkinetic heart syndrome, ${ }^{24}$ hyperventilation, ${ }^{29}$ postural changes, ${ }^{30}$ or emotion. The ability of propranolol to abolish functional ischaemic-like electrocardiographic resting changes in the absence of coronary heart disease has also been described. ${ }^{31-33}$ However, none of the patients had coronary arteriograms, and classification was based purely on clinical criteria. Furthermore, this otherwise similar group of subjects with dominant sympathetic hyperactivity is in striking contrast to our group 2 , in whom resting heart rate was low.

Several possible causes of false positive electrocardiographic response to exercise must be excluded if the specificity for coronary heart disease is to be increased. These include hypertrophic cardiomyopathy, asymmetric septal hypertrophy, and prolapsing mitral valve, ${ }^{317}$ and patients with these conditions were excluded by echocardiography before this study. Other causes such as digoxin or other drugs, metabolic disturbances such as hypokalaemia, conduction abnormalities, and the syndrome of vasoregulatory asthenia were also excluded. In this study of men it is not necessary to consider other causes of false positive response to exercise which occur predominantly in women.

In this study, oxprenolol reversed many, but not all, of the resting electrocardiographic abnormalities of group 1 patients with obstructed coronary arteries. Oxprenolol also reversed many, but again not all, of the resting electrocardiographic changes of group 2 subjects with normal coronary arteries. It is obvious from these observations that, on the basis of its effect on the resting electrocardiogram, beta-blockade is not useful for identifying patients with coronary heart disease.

The effect of beta-blockade on the electrocardiographic response to exercise, however, was different. In patients with angina (group 1), oxprenolol had no effect on the true positive electrocardiographic response to exercise of the 43 patients with obstructed coronary arteries, but did restore to normal the exercise electrocardiogram of the single patient whose coronary arteriogram was subsequently shown to be normal. It thus improved the specificity from 75 to 100 per cent and the predictive value from 98 to 100 per cent without reducing the sensitivity, which remained at 93 per cent (Table 4).

In group 2, oxprenolol restored to normal all the 19 false positive electrocardiographic responses to exercise, but not the response of the one patient with significant coronary artery obstruction. The specificity was thus increased from 60 to 100 per cent and the predictive value from 5 to 100 per cent. The sensitivity, at 50 per cent, remained unchanged (Table 4). In no case did beta-blockade abolish the true positive electrocardiographic response to the exercise test. It should be noted that, while at the maximal heart rate after beta-blockade the electrocardiographic response to exercise was negative, at the corresponding heart rate during the 'unblocked' test it was positive, indicating that the electrocardiographic improvement was not a heart rate effect (Fig. 9).

In group 2, eight out of 30 who had a negative electrocardiographic response to exercise had an abnormal electrocardiogram before, and during early phases of, the 'unblocked' exercise test; the electrocardiogram became normal at maximum exercise and returned to abnormal during the late recovery period. These tests were regarded as

Table 4 Sensitivity, specificity, and predictive value in groups 1 and 2 before and after beta-blockade

\begin{tabular}{lcc}
\hline & No medication & Oxprenolol \\
\hline Group 1: 50 patients with angina & $(\%)$ & $(\%)$ \\
& 93 & 93 \\
Sensitivity & 75 & 100 \\
Specificity & 98 & 100 \\
Predictive value & & \\
& & \\
Group 2: 50 symptomless subjects with abnormal electrocardiogram & $(\%)$ \\
Sensitivity & $(\%)$ & 50 \\
Specificity & 50 & 100 \\
Predictive value & 60 & 100 \\
& 5 & \\
\hline
\end{tabular}
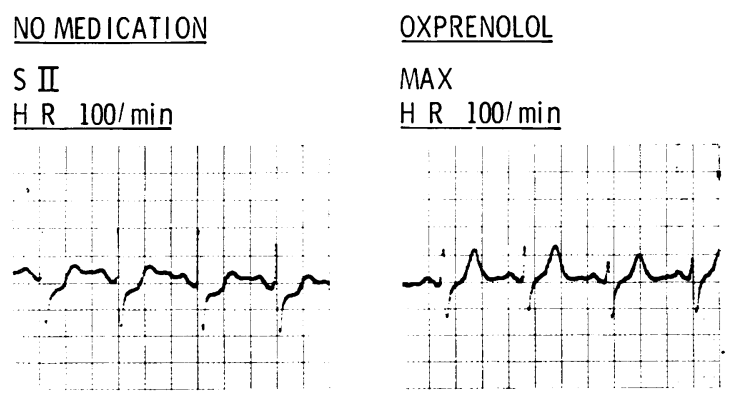

Fig. 9 Exercise electrocardiograms of an asymptomatic subject with a normal coronary arteriogram. Leftpositive at HR 100/min, without medication. Rightnegative at $H R 100 / \mathrm{min}$, one and a half hours after $80 \mathrm{mg}$ oxprenolol. $S$, stage of exercise procedure; $H R$, heart rate. 
negative because it is unlikely that, in the presence of coronary artery obstruction, the electrocardiogram could become normal with increasing heart rate and oxygen demand. We have seen no such electrocardiographic response in patients with coronary heart disease nor, to the best of our knowledge, has it been reported. However, even if this type of response is classified as positive, the subsequent exercise test after beta-blockade was normal throughout in these patients. Our findings are in agreement with those of Furberg ${ }^{31}$ and Kattus et al. ${ }^{30}$ who found that beta-blockade did not abolish electrocardiographic abnormalities in patients with organic disease on exercise, but did abolish resting electrocardiographic abnormalities when these were functional. These data lead to the conclusion that beta-blockade will abolish a false positive electrocardiographic response to exercise but will not affect a true positive response.

The use of exercise testing for detection of myocardial ischaemia in patients with abnormal electrocardiograms at rest, similar to our group 2, has been recently reported by Surawicz and Saito ${ }^{34}$; however, they did not use beta-blockade in such patients with false positive tests.

Our results are in keeping with the hypothesis of Taggart et al. ${ }^{8}$ that the electrocardiographic changes resembling myocardial ischaemia in the presence of normal coronary arteries are the result of altered myocardial sensitivity to normal levels of circulating catecholamines. They showed that exercise-induced electrocardiographic changes resembling those of ischaemia may be mimicked by adrenaline infusion, and now it appears that they may be blocked by beta-blockade.

The groups reported in this study were small, and more cases must be investigated to establish what effect beta-blockade has on the electrocardiographic response to exercise of those who present with pain resembling angina but with normal coronary arteries. It is also premature to extrapolate from group 2, consisting of asymptomatic individuals with abnormal resting electrocardiograms, to patients with coronary heart disease who do not have chest pain. The number of patients with coronary heart disease in our group 2 was small, and further work is in progress to confirm our initial findings. Furthermore, the two groups of patients presented here were selected, so that it is inappropriate to apply any conclusions to a random population. However, if our observations are confirmed, the need for coronary arteriography will be much reduced, both in symptom-free people with abnormal resting electrocardiograms and in symptomatic individuals with normal or abnormal resting electrocardiograms and positive electro- cardiographic response to exercise. The procedure described should then become routine in the investigation of coronary heart disease.

\section{References}

${ }^{1}$ Redwood DR, Borer JS, Epstein SE. Whither the ST segment during exercise? Circulation 1976; 54: 703-6. ${ }^{2}$ Sheffield LT, Reeves TJ, Blackburn $\mathrm{H}$, et al. The exercise test in perspective. Circulation 1977; 55: 681-3. ${ }^{3}$ Zohman LR, Kattus AA. Exercise testing in the diagnosis of coronary heart disease: a perspective. $\mathrm{Am}$ $\mathcal{f}$ Cardiol 1977; 40: 243-50.

${ }^{4}$ Bruce RA, McDonough JR. Stress testing in screening for cardiovascular disease. Bull NY Acad Med 1969; 45: 1288-305.

${ }^{5} \mathrm{McHenry} \mathrm{PK}$. The actual prevalence of false positive ST segment responses to exercise in clinically normal subjects remains undefined. Circulation 1977; 55: 683-5.

${ }^{6}$ Epstein SE. Value and limitations of the electrocardiographic response to exercise in the assessment of patients with coronary artery disease. $\mathrm{Am} \mathcal{F}$ Cardiol 1978; 42: 667-74.

${ }^{7}$ Garrison GE, Cullen WH. Post-exercise electrocardiograms, coronary heart disease and airline pilots. Aerospace Med 1972; 43: (1) 86-91.

${ }^{8}$ Taggart P, Carruthers M, Joseph S, et al. Electrocardiographic changes resembling myocardial ischaemia in asymptomatic men with normal coronary arteriograms. Br Heart f 1979; 41: 214-25.

'Doan AG, Peterson DR, Blackman JR, Bruce RA. Myocardial ischaemia after maximal exercise in healthy men. A method of detecting potential coronary heart disease. Am Heart $\mathcal{f}$ 1965; 69: 11-21.

${ }^{10}$ Hamilton GW, Trobauch GB, Narahara KA, Williams DL, Ritchie JL. Thallium-201 myocardial imaging at rest and maximal exercise for the detection of coronary artery disease (abstract). Am f Cardiol 1977; 39: 321. "Botvinick EH, Taradash MR, Shames DM, Parmley WW. Thallium-201 myocardial perfusion scintigraphy for the clinical clarification of normal, abnormal and equivocal electrocardiographic stress tests. $A m \mathcal{F}$ Cardiol 1978; 41: 43-51.

${ }^{12}$ Ritchie JL, Trobaugh GB, Hamilton GW, et al. Myocardial imaging with Thallium-201 at rest and during exercise. Circulation 1977; 56: 66-71.

${ }^{13}$ Morris SN, McHenry PL. Role of exercise stress testing in healthy subjects and patients with coronary heart disease. Am $\mathcal{F}$ Cardiol 1978; 42: 659-66.

${ }^{14}$ Weiner DA, McCabe C, Hyeter DC, Ryan TJ, Hood WB Jr. The predictive value of anginal chest pain as an indicator of coronary disease during exercise testing. Am Heart f 1978; 96: 458-62.

${ }^{15}$ Ellestad MH, Wan MKC. Predictive implications of stress testing. Follow-up of 2700 subjects after maximum treadmill stress testing. Circulation 1975; 51: 363-9.

${ }^{16}$ Thomson PD, Keleman MH. Hypotension accompanying the onset of exertional angina. Circulation 1975; 52: 28-32. 
${ }^{17}$ Ellestad MH, Savitz S, Bergdall D, Teske J. The false positive stress test. Multivariate analysis of 215 subjects with hemodynamic, angiographic and clinical data. Am f Cardiol 1977; 40: 681-5.

${ }^{18}$ Berman JL, Wynne J, Cohn PF. A multivariate approach for interpreting treadmill exercise tests in coronary artery disease. Circulation 1978; 58: 505-12.

${ }^{19}$ Selzer A, Cohn K, Goldschlager N. On the interpretation of the exercise test. Circulation 1978; 58: 193-5.

${ }^{20}$ Keleman MH, Gillilan RE, Bouchard RJ, Heppner RL, Warbasse J. Diagnosis of obstructive coronary disease by maximal exercise and atrial pacing. Circulation 1973; 48: 1227-33.

${ }^{21}$ Bartel AG, Behar VS, Peter RH, Orgain ES, Kong Y. Graded exercise stress tests in angiographically documented coronary artery disease. Circulation 1974; 49: 348-56.

${ }^{22}$ Erikssen J, Enge I, Forfang K, Storstein O. False positive diagnostic tests and coronary angiographic findings in 105 presumably healthy males. Circulation 1976; 54: 371-6.

${ }^{23}$ Holmgren A, Johansson B, Levander M, Linderholm H, Sjöstrand T, Ström G. ECG changes in vasoregulatory asthenia and the effect of physical training. Acta Med Scand 1959; 165: 259-71.

${ }^{24}$ Guazzi M, Fiorentini C, Polese A, Magrini F, Olivari MT. Stress-induced and sympathetically-mediated electrocardiographic and circulatory variations in the primary hyperkinetic heart syndrome. Cardiovasc Res 1975 ; 9: 342-54.

${ }^{25}$ Mayerson HS, Davis WD Jr. The influence of posture on the electrocardiogram. Am Heart $\mathcal{F} 1942$; 24: 593-601.

${ }^{26} \mathrm{Kemp}$ GL, Ellestad MH. The significance of hyperventilation and orthostatic $T$ wave changes on the electrocardiogram. Arch Intern Med 1968; 121 : 518-23.
${ }^{27}$ Taggart T, Carruthers $M$, Somerville W. Emotions, catecholamines and the electrocardiogram. In: Yu PN, Goodwin JF, eds. Progress in cardiology. Vol 7. Philadelphia: Lee \& Febiger, 1978: 103-24.

${ }^{28}$ Prichard BNC, Gillam PMS. Assessment of propranolol in angina pectoris. Br Heart $\mathcal{F} 1971$; 33: 473-80.

${ }^{29}$ Furberg C, Tengblad CF. Adrenergic beta receptor blockade and the effect of hyperventilation on the electrocardiogram. Scand f Clin Lab Invest 1966; 18: 467-72.

${ }^{30}$ Kattus AA, MacAlpin RN, Alvaro A. Reversibility of non-ischaemic postural and exercise induced ECG abnormalities of the $T$ wave and ST segments by beta adrenergic blockade. In: Kattus AA, Ross G, Hall VE, eds. Cardiovascular adrenergic responses, UCLA forum series no. 13. Los Angeles: University of California Press, 1970: 3 .

${ }^{31}$ Furberg C. Adrenergic beta-blockade and electrocardiographical ST-T changes. Acta Med Scand 1967; 181: 21-32.

${ }^{32}$ Noskowicz T, Chrzanowski W. The influence of propranolol on functional alterations of the electrocardiogram. Cardiologia 1968; 52: 324-9.

${ }^{33}$ Jackson WB. The use of propranolol in ECG diagnosis. $N Z$ Med f 1971; 73: 65-68.

${ }^{34}$ Surawicz B, Saito S. Exercise testing for detection of myocardial ischemia in patients with abnormal electrocardiograms at rest. Am $\mathcal{f}$ Cardiol 1978; 41: 943-51.

Requests for reprints to Dr J Marcomichelakis, Department of Cardiology, The Middlesex Hospital, London W1N 8AA. 